Article

\title{
Polyphenol Extraction from Humulus lupulus (Hop) Using a Neoteric Glycerol/L-Alanine Deep Eutectic Solvent: Optimisation, Kinetics and the Effect of Ultrasound-Assisted Pretreatment
}

\author{
Achillia Lakka, Ioanna Karageorgou, Olga Kaltsa, Georgia Batra, Eleni Bozinou, Stavros Lalas \\ and Dimitris Makris *
}

School of Agricultural Sciences, University of Thessaly, 43100 Karditsa, Greece

* Correspondence: dimitrismakris@uth.gr; Tel.: +30-24410-64792

Received: 20 July 2019; Accepted: 6 August 2019; Published: 8 August 2019

\begin{abstract}
The investigation presented herein had as its scope the development of an integrated process for the efficient extraction of polyphenols from hop. For this purpose, a novel, natural deep eutectic solvent (DES) was synthesised, composed of glycerol and L-alanine, and the process was optimised by deploying a response surface methodology based on a Box-Behnken design. The variables considered were the DES/water proportion, the liquid-to-solid ratio and the stirring speed. Under the optimised conditions, the yield in total polyphenols achieved was $118.97 \pm 8.27 \mathrm{mg}$ gallic acid equivalents per $\mathrm{g}$ of dry mass. Ultrasonication, incorporated into the process as a pretreatment step, was shown to significantly change the kinetic pattern of polyphenol extraction and contributed to attaining higher yields only at $80^{\circ} \mathrm{C}$, whereas at lower temperatures a supressing effect was observed. Furthermore, increasing temperature was negatively correlated with the second-order extraction rates, evidencing a slow-down of the extraction rate at elevated temperatures.
\end{abstract}

Keywords: antioxidants; deep eutectic solvents; Humulus lupulus; kinetics; polyphenols; ultrasound-assisted extraction

\section{Introduction}

Hop (Humulus lupulus L.) is a plant well-known for its use in brewing, where the female inflorescences (hop cones or "hops"), which are rich in essential oils, resins and various polyphenolic substances, are widely used as a beer flavouring and preservative [1]. However, hop cones have long been used in folk medicine for various disorders, as hop constituents may possess mild sedative, estrogenic and antimicrobial activities, as well as a series of other bioactivities [2,3]. Hop polyphenols comprise almost $4 \%$ of the total hop cone dry mass, and they belong to a wide range of classes, including flavonols, flavanols, prenylated chalcones and flavanones, but also phenolic acids, stilbenes and phloroglucinol derivatives [3,4]. It has been reported that more than 100 different compounds may occur in hop extracts, their profile depending mainly on varietal parameters, lending hop an important prospect as a medicinal plant [5,6].

Polyphenols are a highly versatile group of natural substances, divided into several subclasses, and by virtue of their abundance in a vast spectrum of edible plant materials, they have been a subject of intense research [7]. Some of the major properties of polyphenols associated with their pharmacological potency and biological effects are their antioxidant, anti-inflammatory, cardioprotective and chemopreventive activities [8,9]. There is currently an ever-growing interest in the generation of polyphenol-containing extracts, which possess specific bioactivities and could be used as functional ingredients in foods and/or cosmetics. For this reason, numerous technologies have been developed, 
aimed at a sustainable production of extracts with minimum requirements in solvent and energy, high productivity and low cost [10].

The selection of an appropriate solvent for the development of an efficient extraction process is a dare necessity for the industry, and in the framework of Green Chemistry, the need for designing new eco-friendly processes largely relies on the use of novel, non-toxic and recyclable solvents $[11,12]$. Deep eutectic solvents (DES), some also referred to as low-transition temperature mixtures (LTTMs), are designer liquids composed usually of a constituent serving as a hydrogen bond donor (HBD) and another one serving as a hydrogen bond acceptor (HBA). These neoteric materials have an assortment of peculiar properties, such as low or no volatility and flammability, absence of toxicity, tunability, stability, low cost, recyclability and biodegradability, that make them ideal for the development of green extraction methodologies [13]. Indeed, over the last 3 years, a number of studies demonstrated the efficacy of DES as solvents for task-specific extractions, offering new potential pathways in polyphenol extraction [14].

This being the case, in the study presented herein a task-specific extraction was established offering a green process for the effective extraction of polyphenols from hop, using a newly synthesised deep eutectic solvent, based on glycerol and L-alanine. Response surface methodology was employed to carry out process optimisation, and the effect of temperature was appraised by performing kinetics. To the best of the authors' knowledge, this is the first report on hop polyphenol extraction using DES.

\section{Materials and Methods}

\subsection{Chemicals}

Glycerol anhydrous (99.5\%), L-alanine, ascorbic acid (99.5\%), sodium carbonate anhydrous (99\%), and aluminium chloride anhydrous (98\%) were from Penta (Praha, Czechia). Gallic acid hydrate was from Panreac (Barcelona, Spain). Rutin (quercetin 3-O-rutinoside) hydrate, 2,4,6-tris(2-pyridyl)-s-triazine (TPTZ) and Folin-Ciocalteu reagent were from Sigma-Aldrich (St. Louis, MO, USA). Iron chloride hexahydrate was from Merck (Darmstadt, Germany).

\subsection{Plant Material and Treatments}

The hop (Humulus lupulus) was a kind donation from Pineios Brewery Ltd. (Larisa, Greece), and it was received in the form of pellets, in air-tight plastic packaging. Upon receipt, the plant material was dried at $55^{\circ} \mathrm{C}$ for $24 \mathrm{~h}$ in a laboratory oven (Binder BD56, Bohemia, NY, USA). The dried hop was then ground in a ball-mill to give a powder with an average particle diameter of $0.161 \mathrm{~mm}$, and stored in sealed dark-glass containers, at $-40{ }^{\circ} \mathrm{C}$, until use.

\subsection{Synthesis of DES}

The solvent was prepared according to a methodology reported elsewhere [15]. Precisely weighted amounts of glycerol (hydrogen bond donor) and L-alanine (hydrogen bond acceptor) were introduced into a 500-mL duran bottle and heated at approximately $80-85^{\circ} \mathrm{C}$ under continuous stirring at $400 \mathrm{rpm}$, for a period of $6-7 \mathrm{~h}$, to ensure the formation of a perfectly transparent liquid. After reaching room temperature, the DES, with HBD:HBA ratios varying from 5:1 to 13:1, was stored in a dark and dry chamber, and it was periodically observed for the appearance of crystals by visual inspection, over a period of several weeks, to ascertain its stability.

\subsection{Batch Stirred-Tank Extraction}

A lot of $0.570 \mathrm{~g}$ of dried plant material was transferred into a 50-mL round-bottom flask and $20 \mathrm{~mL}$ of solvent was added, to give a liquid-to-solid ratio $\left(\mathrm{R}_{\mathrm{L} / \mathrm{S}}\right)$ of $35 \mathrm{~mL} \mathrm{~g}^{-1}$. The extraction was accomplished under continuous agitation at $500 \mathrm{rpm}$ for $150 \mathrm{~min}$, at $50{ }^{\circ} \mathrm{C}$, in an oil bath heated by an accurately thermostated hotplate (Witeg, Wertheim, Germany). The extract was centrifuged for $10 \mathrm{~min}$ 
at $10,000 \times g$ prior to analysis. DES used for the extractions were $70 \%(w / w)$ aqueous mixtures. Control extractions were performed with deionised water, $60 \%(v / v)$ methanol and $60 \%(v / v)$ ethanol.

\subsection{Ultrasound-Assisted Pretreatment}

The pretreatment consisted of ultrasonicating the mixture of solvent with the solid material prior to batch stirred-tank extractions. Ultrasonication was performed in an Elma D-78224 Singen HTW heated ultrasonic bath (Elma Schmidbauer $\mathrm{GmbH}$, Singen, Germany), operated at a frequency of $50 \mathrm{~Hz}$, a power of $550 \mathrm{~W}$ and an acoustic energy density of $78.6 \mathrm{~W} \mathrm{~L}^{-1}$. All utrasonication pretreatments were accomplished at ambient temperature $\left(22 \pm 2{ }^{\circ} \mathrm{C}\right)$.

\subsection{Extraction Optimisation by Response Surface Methodology}

The procedure implemented had as its objective to optimise polyphenol recovery from the hop, taking into account three principal process parameters: the concentration of DES in aqueous mixtures $\left(C_{\mathrm{DES}}\right)$, the liquid-to-solid ratio $\left(\mathrm{R}_{\mathrm{L} / \mathrm{S}}\right)$ and the speed of stirring $\left(\mathrm{S}_{\mathrm{S}}\right)$. To accomplish this, an experimental design was set up using a Box-Behnken mode with three central points. The three process variables were assigned as $\mathrm{X}_{1}\left(\mathrm{C}_{\mathrm{DES}}\right), \mathrm{X}_{2}\left(\mathrm{R}_{\mathrm{L} / \mathrm{S}}\right)$ and $\mathrm{X}_{3}\left(\mathrm{~S}_{\mathrm{S}}\right)$, and coded to three levels, from -1 (lower limit) to 1 (upper limit) (Table 1). For the codification, the following equation was used [16]:

$$
\mathrm{X}_{\mathrm{i}}=\left(\frac{z_{i}-z_{1}^{0}}{\Delta z_{i}}\right) \times \beta_{\mathrm{d}}
$$

Table 1. Process variables, their codification and actual and coded levels used for the experimental design implemented.

\begin{tabular}{ccccc}
\hline Independent Variables & Code Units & \multicolumn{2}{c}{ Coded Variable Level } \\
\hline & & $-\mathbf{1}$ & $\mathbf{0}$ & $\mathbf{1}$ \\
\hline $\begin{array}{c}\text { Concentration of DES in aqueous } \\
\text { mixtures, } \mathrm{C}_{\mathrm{DES}}(\%, w / v)\end{array}$ & $\mathrm{X}_{1}$ & 55 & 70 & 85 \\
Liquid-to-solid ratio, $\mathrm{R}_{\mathrm{L} / \mathrm{S}\left(\mathrm{mL} \mathrm{g}^{-1}\right)}$ & $\mathrm{X}_{2}$ & 20 & 40 & 60 \\
Speed of stirring, $\mathrm{S}_{\mathrm{S}}(\mathrm{rpm})$ & $\mathrm{X}_{3}$ & 200 & 500 & 800 \\
\hline
\end{tabular}

$\Delta z_{\mathrm{i}}$ represents the distance between the real value at the central point and the real value in the upper or lower limit of a variable, $\beta_{\mathrm{d}}$ corresponds to the major coded limit value in the matrix for each variable, and $z^{0}$ is the real value at the central point. The polynomial equation (mathematical model), derived by fitting the function to the experimental data, was assessed by analysis of variance (ANOVA) and lack-of-fit. The portrayal of the predicted model equation was obtained by 3D surface response plots.

\subsection{Total Polyphenol (TP) Determination}

A methodology reported elsewhere was used [17]. All samples were diluted 1:50 with 0.5\% formic acid in water prior to determinations. Then, $0.1 \mathrm{~mL}$ of diluted sample was transferred along with $0.1 \mathrm{~mL}$ of Folin-Ciocalteu reagent in a 1.5-mL Eppendorf tube, and the reaction was left to proceed for $2 \mathrm{~min}$. Following this, $0.8 \mathrm{~mL}$ of $\mathrm{Na}_{2} \mathrm{CO}_{3}$ solution $(5 \% \mathrm{w} / \mathrm{v})$ was added, and the mixture was heated in a thermostated water bath (Heidolph HB digital, Schwabach, Germany), at $40{ }^{\circ} \mathrm{C}$, for $20 \mathrm{~min}$. The absorbance was recorded at $740 \mathrm{~nm}$ in a Shimadzu UV-1700 PharmaSpec spectrophotometer (Shimadzu, Kyoto, Japan), and the determination of total polyphenol concentration $\left(C_{\mathrm{TP}}\right)$ was accomplished with a gallic acid calibration curve $\left(10-80 \mathrm{mg} \mathrm{L}^{-1}\right)$. Results were expressed as $\mathrm{mg}$ gallic acid equivalents (GAE) $\mathrm{L}^{-1}$. The extraction yield in total polyphenols was expressed as $\mathrm{mg}$ $\mathrm{GAE} \mathrm{g}^{-1}$ dry mass (dm) [18]. 


\subsection{Total Flavonoid (TFn) Determination}

A previously published protocol was applied [19]. Briefly, a volume of $0.1 \mathrm{~mL}$ of sample was mixed with $0.86 \mathrm{~mL}$ of aqueous ethanol $(35 \% v / v)$ and $0.04 \mathrm{~mL}$ of a reagent containing $0.5 \mathrm{M}$ sodium acetate and $5 \%(w / v)$ aluminium chloride. The mixture was allowed to react for $30 \mathrm{~min}$ at room temperature, and then the absorbance was obtained at $415 \mathrm{~nm}$. Total flavonoid concentration $\left(C_{\mathrm{TFn}}\right)$ was calculated with a rutin (quercetin 3-O-rutinoside) calibration curve $\left(15-300 \mathrm{mg} \mathrm{L}^{-1}\right)$. Total flavonoid yield $\left(\mathrm{Y}_{\mathrm{TFn}}\right)$ was estimated as $\mathrm{mg}$ rutin equivalents (RtE) per $\mathrm{g} \mathrm{dm}$.

\subsection{Total Flavanol (TF) Determination}

Total flavanols were determined using the $p$-dimethylaminocinnamaldehyde (DMACA) assay [20], with some modifications. Each sample was first diluted 1:50 with methanol. An aliquot of $0.02 \mathrm{~mL}$ of diluted sample was placed in a 1.5-mL Eppendorf tube with $0.88 \mathrm{~mL} \mathrm{HCl} \mathrm{(2} \mathrm{M} \mathrm{in} \mathrm{methanol)} \mathrm{and}$ $0.1 \mathrm{~mL}$ DMACA $(0.1 \%$ w/v in methanol). The mixture was allowed to react for $15 \mathrm{~min}$ before reading the absorbance at $640 \mathrm{~nm}$. The concentration of total flavanols $\left(C_{\mathrm{TF}}\right)$ was estimated from a catechin calibration curve (1-80 $\mathrm{mg} \mathrm{L}^{-1}$ ) and expressed as catechin equivalents (CtE). Extraction yield in TF $\left(\mathrm{Y}_{\mathrm{TF}}\right)$ was given as $\mathrm{mg} \mathrm{CtE}^{-1} \mathrm{dm}$.

\subsection{Determination of the Antiradical Activity $\left(A_{A R}\right)$}

A stoichiometric methodology previously published was used [21], using DPPH. The extract was diluted 1:50 with methanol, and $0.025 \mathrm{~mL}$ of the diluted sample was mixed with $0.975 \mathrm{~mL} \mathrm{DPPH}$ $(100 \mu \mathrm{M}$ in methanol) and incubated at ambient temperature. The absorbance at $515 \mathrm{~nm}$ was measured at $t=0 \min \left(\mathrm{A}_{515(\mathrm{i})}\right)$ and at $t=30 \mathrm{~min}\left(\mathrm{~A}_{515(\mathrm{f})}\right)$. The $\mathrm{A}_{\mathrm{AR}}$ of the extract was determined as follows:

$$
\mathrm{A}_{\mathrm{AR}}=\frac{\Delta \mathrm{A}}{\varepsilon \times l \times C} \times \mathrm{Y}_{\mathrm{TCn}}
$$

where $\Delta \mathrm{A}=\mathrm{A}_{515(\mathrm{i})}-\mathrm{A}_{515(\mathrm{f})}, \varepsilon(\mathrm{DPPH})=11,126 \times 10^{6} \mu \mathrm{M}^{-1} \mathrm{~cm}^{-1}, \mathrm{C}=\mathrm{C}_{\mathrm{TP}} \times 0.025 \times$ dilution $(1 / 50)$, $\mathrm{Y}_{\mathrm{TP}}$ is the extraction yield $\left(\mathrm{mg} \mathrm{g}^{-1}\right)$ in TP of the extract, and $l$ is the path length $(1 \mathrm{~cm}) . \mathrm{A}_{\mathrm{AR}}$ was expressed as $\mu \mathrm{mol} \mathrm{DPPH} \mathrm{g}^{-1} \mathrm{dm}$.

\subsection{Determination of the Reducing Power $\left(P_{R}\right)$}

$\mathrm{P}_{\mathrm{R}}$ was estimated according to a published methodology [22]. Volumes of $0.05 \mathrm{~mL}$ of extract and $0.05 \mathrm{~mL}$ of $\mathrm{FeCl}_{3}(4 \mathrm{mM}$ in $0.05 \mathrm{M} \mathrm{HCl})$ were placed in a 1.5-mL Eppendorf tube, and the reaction was carried out for $30 \mathrm{~min}$ at $37^{\circ} \mathrm{C}$, in a water bath. Then, $0.9 \mathrm{~mL}$ of TPTZ solution $(1 \mathrm{mM}$ in $0.05 \mathrm{M}$ $\mathrm{HCl}$ ) was added, and after $10 \mathrm{~min}$ the absorbance was recorded at $620 \mathrm{~nm} . \mathrm{P}_{\mathrm{R}}$ was determined as $\mu \mathrm{M}$ ascorbic acid equivalents (AAE) per g dry mass, using an ascorbic acid calibration curve (50-300 $\mu \mathrm{M})$.

\subsection{Statistical Analyses}

Extractions were performed at least twice, and determinations were performed in triplicate. Values are reported are means \pm standard deviation. Statistical analyses for the Box-Behnken design, response surface methodology and distributions were performed with JMPTM Pro 13 (SAS, Cary, NC, USA), at a 95\% significance level. Kinetics was traced with SigmaPlot 12.5 (Systat Software Inc., San Jose, CA, USA).

\section{Results and Discussion}

\subsection{DES Synthesis and HBD:HBA Molar Ratio $\left(R_{\text {mol }}^{D / A}\right)$ Assay}

L-Alanine is a natural amino acid that has been poorly investigated as a HBA for DES synthesis. L-Lactic acid/L-alanine-based DES have been reported for the extraction of antioxidant phenolics from various industrial cereal solid wastes [14], but to the best of the authors' knowledge, there is only one 
report on glycerol/L-alanine-based DES, used for the extraction of rutin (quercetin 3-O-rutinoside) from tartary buckwheat hulls [23]. In the latter study, the synthesis of a DES composed of glycerol/L-alanine with a molar ratio $\left(\mathrm{R}_{\mathrm{mol}}^{\mathrm{D} / \mathrm{A}}\right)$ of 3 was claimed, but in this examination, no stable DES could be prepared below a $\mathrm{R}_{\mathrm{mol}}^{\mathrm{D} / \mathrm{A}}$ of 5 . Thus, the DES screened for polyphenol extraction efficiency were glycerol/L-alanine with $R_{\text {mol }}^{\mathrm{D} / \mathrm{A}}$ of $5,7,9,11$ and 13.

The importance of $\mathrm{R}_{\text {mol }}^{\mathrm{D} / \mathrm{A}}$ has been well documented in earlier investigations, which stressed that polyphenol extraction yield may vary largely, depending on the relevant amounts of HBD and HBA [15,24-26]. This is because switching $\mathrm{R}_{\mathrm{mol}}^{\mathrm{D} / \mathrm{A}}$ causes changes in crucial physicochemical properties of DES, such as viscosity and polarity, which in turn may greatly affect extraction performance. However, there has been no consistent pattern established between $\mathrm{R}_{\text {mol }}^{\mathrm{D} / \mathrm{A}}$ and extraction yield. Indeed, it can be seen in Figure 1 that from $R_{\text {mol }}^{\mathrm{D} / \mathrm{A}} 5$ to 9 , a gradual decline in $\mathrm{Y}_{\mathrm{TP}}$ was observed, but extraction with the DES glycerol:alanine (GL-Ala) (11:1) gave higher $\mathrm{Y}_{\mathrm{TP}}$ than GL-Ala (9:1), which was again reduced when GL-Ala (13:1) was used. GL-Ala (5:1) displayed outstanding extraction capacity, as it provided extracts with a $13 \%$ higher yield than that of $60 \%$ methanol and a $22.4 \%$ higher yield than that of $60 \%$ ethanol. Among all DES tested, GL-Ala gave significantly higher $\mathrm{Y}_{\mathrm{TP}}(p<0.05)$, amounting to $92.75 \pm 3.71 \mathrm{mg} \mathrm{GAE} \mathrm{g}^{-1} \mathrm{dm}$.

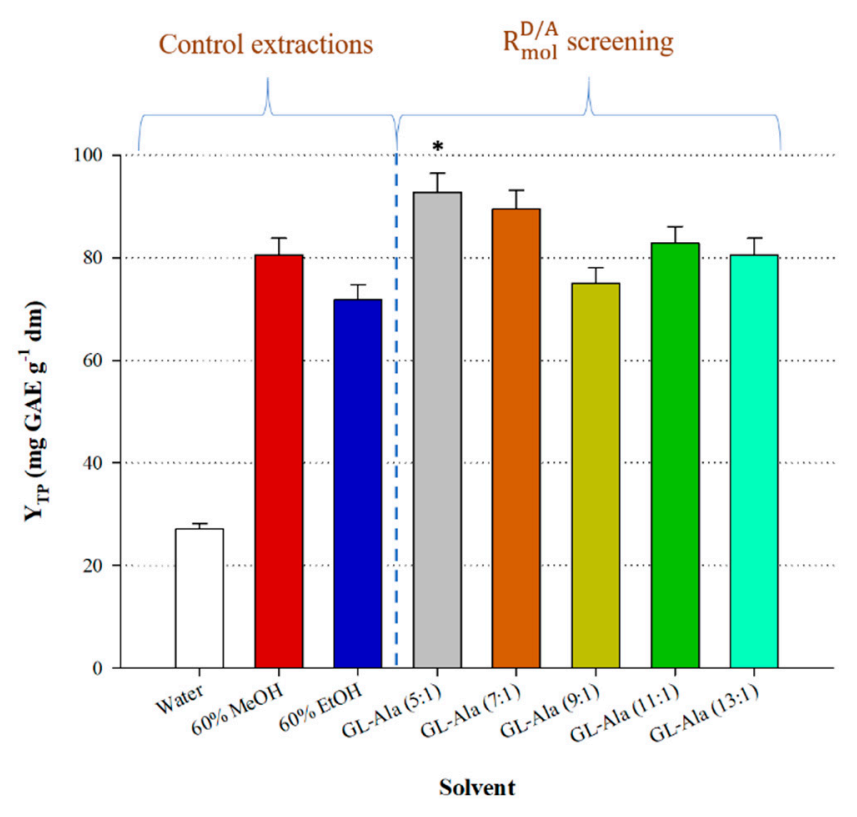

Figure 1. Graph illustrating the effect of molar HBD:HBA (hydrogen bond acceptor:hydrogen bond donor) ratio (dimensionless) $\left(\mathrm{R}_{\mathrm{mol}}^{\mathrm{D} / \mathrm{A}}\right)$ on the extraction efficiency of the deep eutectic solvent (DES) tested. Screening extractions were performed at $50{ }^{\circ} \mathrm{C}$, with $C_{\mathrm{DES}}=70 \%(w / w)$, at $500 \mathrm{rpm}$, for $150 \mathrm{~min}$. The asterisk denotes a statistically higher value $(p<0.05)$.

To obtain a wider picture of the potency of GL-Ala (5:1) for polyphenol extraction, four additional indices were considered; yield in total flavonoids $\left(\mathrm{Y}_{\mathrm{TFn}}\right)$ and total flavanols $\left(\mathrm{Y}_{\mathrm{TF}}\right)$, as well as the antiradical activity $\left(\mathrm{A}_{\mathrm{AR}}\right)$ and the ferric-reducing power $\left(\mathrm{P}_{\mathrm{R}}\right)$ of the extracts. Compared with $60 \%$ ethanol, which was the most efficient control solvent, the extraction with GL-Ala (5:1) gave a 52.6\% lower flavonoid yield, a 23.7\% lower flavanol yield and a 38\% lower $\mathrm{A}_{\mathrm{AR}}$. However, GL-Ala (5:1) produced an extract with a $29.2 \%$ higher $\mathrm{P}_{\mathrm{R}}$ (Figure 2). 


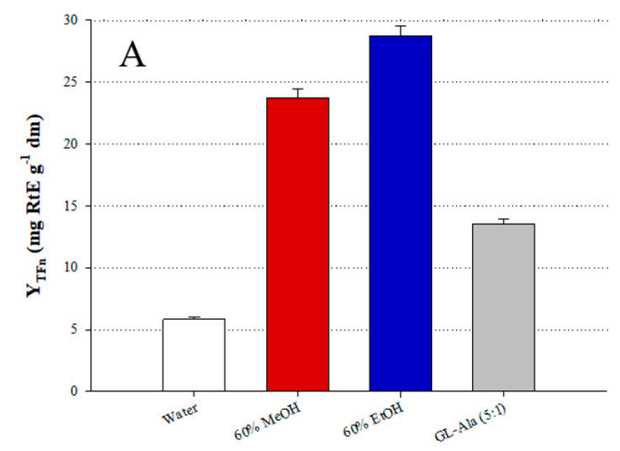

Solven $t$

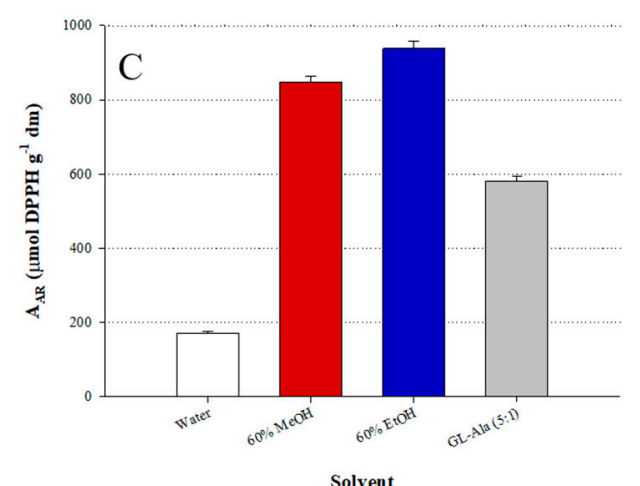

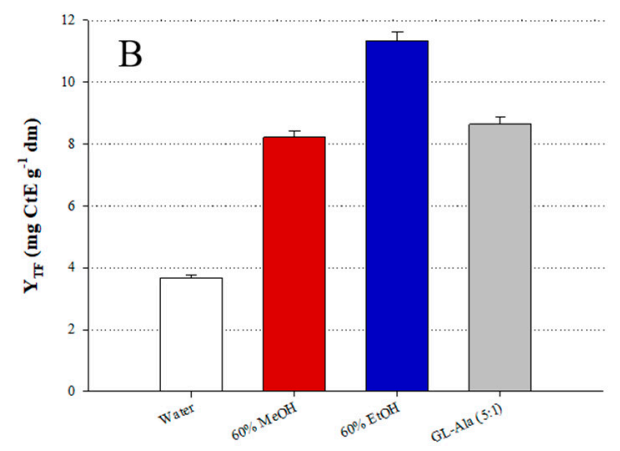

Solvent

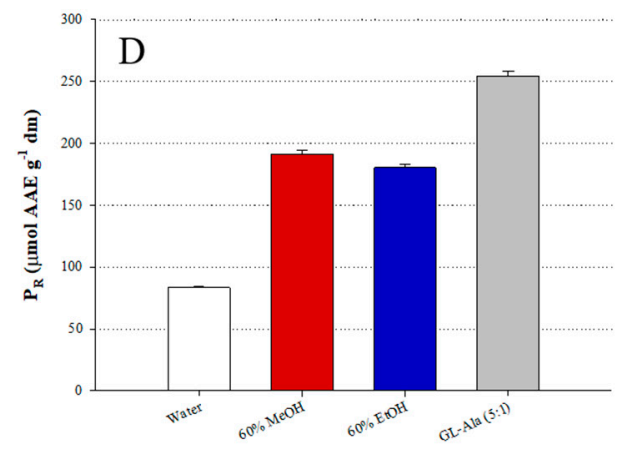

Solvent

Figure 2. Comparative assessment of the DES glycerol/alanine (GL-Ala) (5:1) with regard to yield in total flavonoids $\left(\mathrm{Y}_{\mathrm{TFn}}\right)(\mathrm{A})$, yield in total flavanols $\left(\mathrm{Y}_{\mathrm{TF}}\right)(\mathbf{B})$, antiradical activity $\left(\mathrm{A}_{\mathrm{AR}}\right)(\mathbf{C})$, and ferric-reducing power $\left(\mathrm{P}_{\mathrm{R}}\right)(\mathrm{D})$.

\subsection{Optimisation of Extraction Performance}

The scope of the response surface implementation was the building of a predictive mathematical tool describing the effect of the process variables considered, namely, $C_{\mathrm{DES}}, \mathrm{R}_{\mathrm{L} / \mathrm{S}}$ and $\mathrm{S}_{\mathrm{S}}$, on the total polyphenol yield $\left(\mathrm{Y}_{\mathrm{TP}}\right)$, which was chosen as the response. The influence exerted by each of the variables and the response surface adequacy were appraised by ANOVA and lack-of-fit (Figure 3), and non-significant terms were omitted accordingly. Regarding the model (2nd degree mathematical equation), the square correlation coefficient $\left(R^{2}\right)$ was the indication of the total variability around the mean estimated by the model:

$$
\mathrm{Y}_{\mathrm{TP}}=102.49+15.76 \mathrm{X}_{1}+10.15 \mathrm{X}_{2}+4.68 \mathrm{X}_{1} \mathrm{X}_{3}-6.05 \mathrm{X}_{1}^{2}-5.69 \mathrm{X}_{2}^{2}\left(\mathrm{R}^{2}=0.98, p=0.0009\right)
$$

Considering $\mathrm{R}^{2}$ and the $p$-value, and a confidence interval of $95 \%$, the model derived was highly significant, suggesting that Equation (3) gave excellent adjustment to the experimental data. Table 2 presents analytically the design points of the model, the measured and predicted $Y_{T P}$ values. The 3D plots constructed on the basis of the model (Figure 4) depict the effect of the experimental variables on the response $\left(\mathrm{Y}_{\mathrm{TP}}\right)$. The maximisation of desirability (Figure 3) enabled the prediction of a recommended setting to achieve the highest response: $C_{\mathrm{DES}}=85 \%(w / w), \mathrm{R}_{\mathrm{L} / \mathrm{S}}=59 \mathrm{~mL} \mathrm{~g}^{-1}$ and $\mathrm{S}_{\mathrm{S}}=$ $688 \mathrm{rpm}$. At those inputs, the theoretically optimal yield was estimated to be $118.97 \pm 8.27 \mathrm{mg} \mathrm{GAE} \mathrm{g}^{-1}$ $\mathrm{dm}$, predicted with a $95 \%$ confidence interval. 


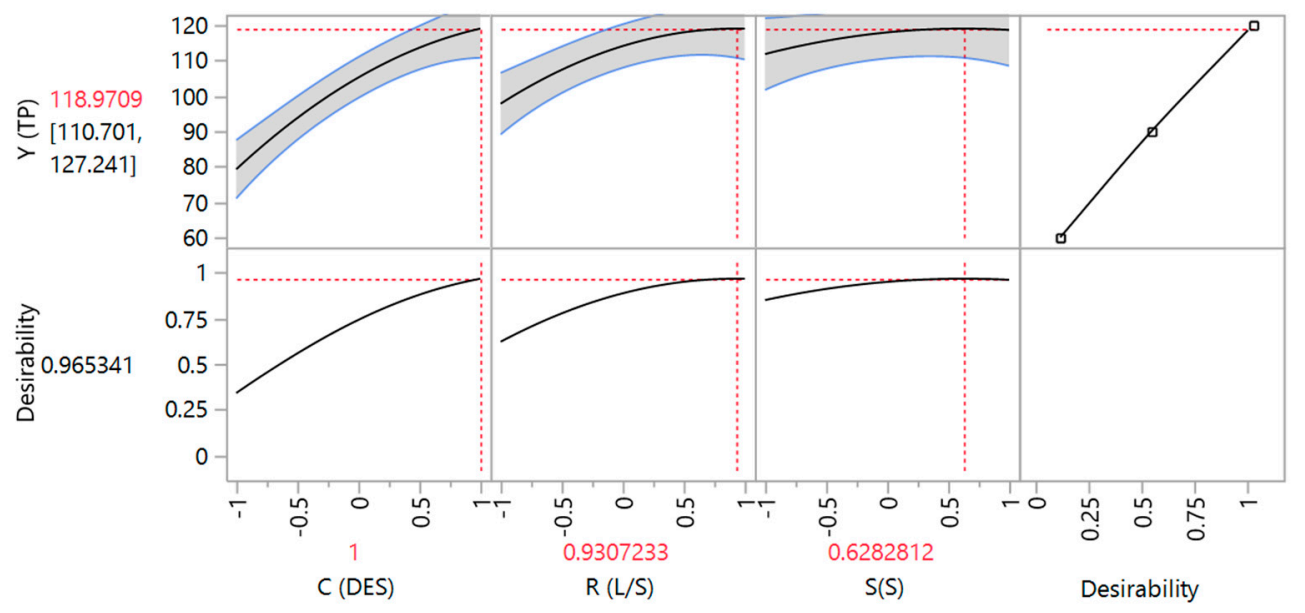

\begin{tabular}{|c|c|c|c|c|}
\hline \multicolumn{5}{|c|}{ Parameter Estimates } \\
\hline Term & Estimate & Std Error & t Ratio & Prob $>|t|$ \\
\hline Intercept & 102.49 & 2.019284 & 50.76 & $<.0001^{*}$ \\
\hline$C(D E S)$ & 15.75875 & 1.236554 & 12.74 & $<.0001^{*}$ \\
\hline$R(L / S)$ & 10.15125 & 1.236554 & 8.21 & $0.0004^{*}$ \\
\hline$S(S)$ & -0.0475 & 1.236554 & -0.04 & 0.9708 \\
\hline$C(D E S)^{*} R(L / S)$ & 1.265 & 1.748751 & 0.72 & 0.5019 \\
\hline$C(D E S)^{*} S(S)$ & 4.6775 & 1.748751 & 2.67 & $0.0441^{*}$ \\
\hline$R(L / S)^{*} S(S)$ & -1.3125 & 1.748751 & -0.75 & 0.4867 \\
\hline$C(D E S)^{*} C(D E S)$ & -6.045 & 1.820158 & -3.32 & $0.0210^{*}$ \\
\hline$R(L / S)^{*} R(L / S)$ & -5.69 & 1.820158 & -3.13 & $0.0261^{*}$ \\
\hline$S(S) * S(S)$ & -2.7125 & 1.820158 & -1.49 & 0.1963 \\
\hline
\end{tabular}

\begin{tabular}{|c|c|c|c|c|c|}
\hline \multicolumn{6}{|l|}{ Effect Tests } \\
\hline Source & Nparm & DF & $\begin{array}{l}\text { Sum of } \\
\text { Squares }\end{array}$ & F Ratio & Prob $>$ F \\
\hline$C$ (DES) & 1 & 1 & 1986.7056 & 162.4117 & $<.0001^{*}$ \\
\hline$R(L / S)$ & 1 & 1 & 824.3830 & 67.3927 & $0.0004^{*}$ \\
\hline $\mathrm{S}(\mathrm{S})$ & 1 & 1 & 0.0181 & 0.0015 & 0.9708 \\
\hline$C(D E S)^{*} R(L / S)$ & 1 & 1 & 6.4009 & 0.5233 & 0.5019 \\
\hline$C(D E S)^{*} S(S)$ & 1 & 1 & 87.5160 & 7.1544 & $0.0441^{*}$ \\
\hline$R(L / S)^{*} S(S)$ & 1 & 1 & 6.8906 & 0.5633 & 0.4867 \\
\hline$C(D E S)^{*} C(D E S)$ & 1 & 1 & 134.9244 & 11.0300 & $0.0210^{*}$ \\
\hline$R(L / S)^{\star} R(L / S)$ & 1 & 1 & 119.5425 & 9.7725 & $0.0261^{*}$ \\
\hline $\mathrm{S}(\mathrm{S})^{\star} \mathrm{S}(\mathrm{S})$ & 1 & 1 & 27.1667 & 2.2209 & 0.1963 \\
\hline
\end{tabular}

Figure 3. Statistical data on the evaluation of the model, derived by implementing response surface methodology.

Table 2. Points of the experimental design and the corresponding measured and predicted response values.

\begin{tabular}{cccccc}
\hline Design Point & \multicolumn{3}{c}{ Independent Variables } & \multicolumn{3}{c}{ Response } \\
\hline & $\mathcal{C}_{\mathbf{D E S}}\left(\mathbf{X}_{\mathbf{1}}\right)$ & $\mathbf{R}_{\mathbf{L} / \mathbf{S}}\left(\mathbf{X}_{\mathbf{2}}\right)$ & $\mathbf{S}_{\mathbf{S}}\left(\mathbf{X}_{\mathbf{3}}\right)$ & $\begin{array}{c}\text { Yield in Total Polyphenols, } \mathbf{Y}_{\mathbf{T P}}(\mathbf{m g} \text { Gallic } \\
\text { Acid Equivalents (GAE) } \mathbf{g}^{\mathbf{- 1}} \text { Dry Mass (dm)) }\end{array}$ \\
\hline & & & & Measured & Predicted \\
\hline 1 & -1 & -1 & 0 & 64.57 & 66.11 \\
2 & -1 & 1 & 0 & 86.98 & 83.88 \\
3 & 1 & -1 & 0 & 92.00 & 95.10 \\
4 & 1 & 1 & 0 & 119.47 & 117.93 \\
5 & 0 & -1 & -1 & 85.54 & 82.67 \\
6 & 0 & -1 & 1 & 86.97 & 85.20 \\
7 & 0 & 1 & -1 & 103.83 & 105.60 \\
8 & 0 & 1 & 1 & 100.01 & 82.70 \\
9 & -1 & 0 & -1 & 81.37 & 104.86 \\
10 & 1 & 0 & -1 & 105.09 & 73.25 \\
11 & -1 & 0 & 1 & 73.02 & 102.12 \\
12 & 1 & 0 & 1 & 115.45 & 102.49 \\
13 & 0 & 0 & 0 & 102.08 & 102.49 \\
14 & 0 & 0 & 0 & 105.00 & \\
15 & 0 & 0 & 0 & 100.39 & \\
\hline
\end{tabular}



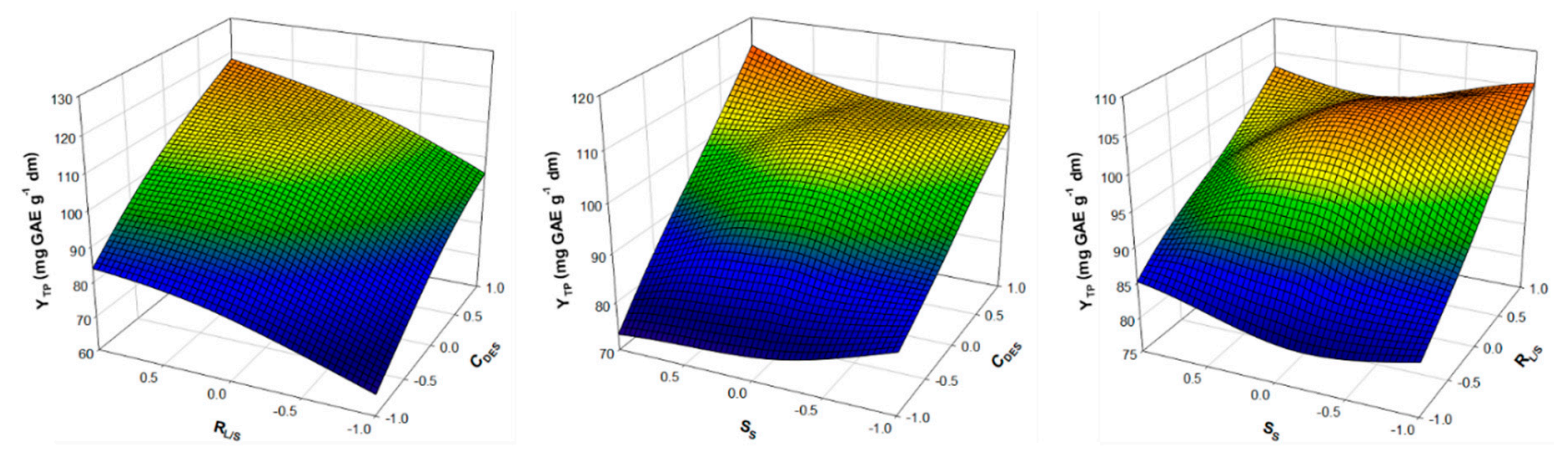

Figure 4. 3D graphs displaying variations in the response as a function of different variable levels.

$C_{\text {DES }}\left(X_{1}\right)$ was found to profoundly affect $Y_{T P}$ (Figure 3), and the optimal level determined was in line with several previous investigations on polyphenol extraction with DES, which suggested $80 \%(w / w)$ to be the most effective DES/water proportion [23,25-28]. Mixing DES with water at an appropriate molar ratio is considered essential in achieving high extraction yields, because water may effectively regulate solvent properties pertaining to solid-liquid extraction, such as polarity and viscosity [29]. Polyphenol extraction is a diffusion-controlled process and may be greatly facilitated by low viscosity [18]. Since DES usually possess high viscosities, the addition of water contributes to decreasing viscosity and increasing diffusivity. Likewise, $\mathrm{R}_{\mathrm{L} / \mathrm{S}}\left(\mathrm{X}_{2}\right)$, which was also a highly significant variable (Figure 3), may affect $Y_{\mathrm{TP}}$ through the modification of diffusivity. The concentration gradient between the solid particles and the liquid phase is the driving force of polyphenol diffusion. The higher the solid/liquid ratio, the higher the concentration gradient, hence the increased rate of diffusion [30,31]. Such a phenomenon has recently been well documented, by correlating $\mathrm{R}_{\mathrm{L} / \mathrm{S}}$ with diffusivity [32]. Previously published examinations showed that optimal $\mathrm{R}_{\mathrm{L} / \mathrm{S}}$ levels for polyphenol extraction with DES may vary within $29-50 \mathrm{~mL} \mathrm{~g}^{-1}$ [33-35]. The optimal value reported in this study $\left(59 \mathrm{~mL} \mathrm{~g}^{-1}\right)$ is of similar magnitude.

$\mathrm{S}_{\mathrm{S}}\left(\mathrm{X}_{3}\right)$ was not statistically significant (Figure 3$)$, but cross effects between $C_{\mathrm{DES}}\left(\mathrm{X}_{1}\right)$ and $\mathrm{S}_{\mathrm{S}}\left(\mathrm{X}_{3}\right)$ were statistically significant with positive contribution to $\mathrm{Y}_{\mathrm{TP}}$. This outcome indicated a combined effect of $C_{\mathrm{DES}}$ and $\mathrm{S}_{\mathrm{S}}$ on $\mathrm{Y}_{\mathrm{TP}}$. Based on the model derived (Equation (3)), increases in either $C_{\mathrm{DES}}$ or $\mathrm{S}_{\mathrm{S}}$, within the pre-set limits, would provoke significant increases in the response $\left(\mathrm{Y}_{\mathrm{TP}}\right)$. A sufficient level of $\mathrm{S}_{\mathrm{S}}$ could induce turbulence in the extraction vessel, which in turn could entail increased mass transfer rate. This is the most probable reason for the increased polyphenol diffusivity as a response to rising $\mathrm{S}_{\mathrm{S}}$ [32]. A suitable $\mathrm{S}_{\mathrm{S}}$ adjustment was found to play a key role in polyphenol extraction processes, providing significantly higher yields [32,36].

\subsection{Ultrasound-Assisted Pretreatment: Effect on Extraction Kinetics}

Despite its wide applicability as a green means of polyphenol extraction, there is substantial evidence that ultrasonication may not be as effective as stirred-tank mode or microwave-assisted extraction [37]. However, it was recently demonstrated that ultrasonication may be very effectively incorporated into a batch stirred-tank extraction process as a pretreatment step, provoking significantly increased polyphenol recovery [38].

Thus, in order to investigate whether an ultrasound-assisted pretreatment step could have an important impact on $\mathrm{Y}_{\mathrm{TP}}$, the ultrasonication time was first examined. Samples were ultrasonicated under constant operating settings (power $550 \mathrm{~W}$, frequency $50 \mathrm{~Hz}$, acoustic energy density $78.6 \mathrm{~W} \mathrm{~L}^{-1}$ ) for various periods, prior to stirred-tank extraction under optimised conditions, as described in paragraph 3.3. A 15-min regime was shown to afford a $Y_{T P}$ result comparable to control (no ultrasonication pretreatment), but a 20-min ultrasonication gave statistically higher values (Figure 5). 


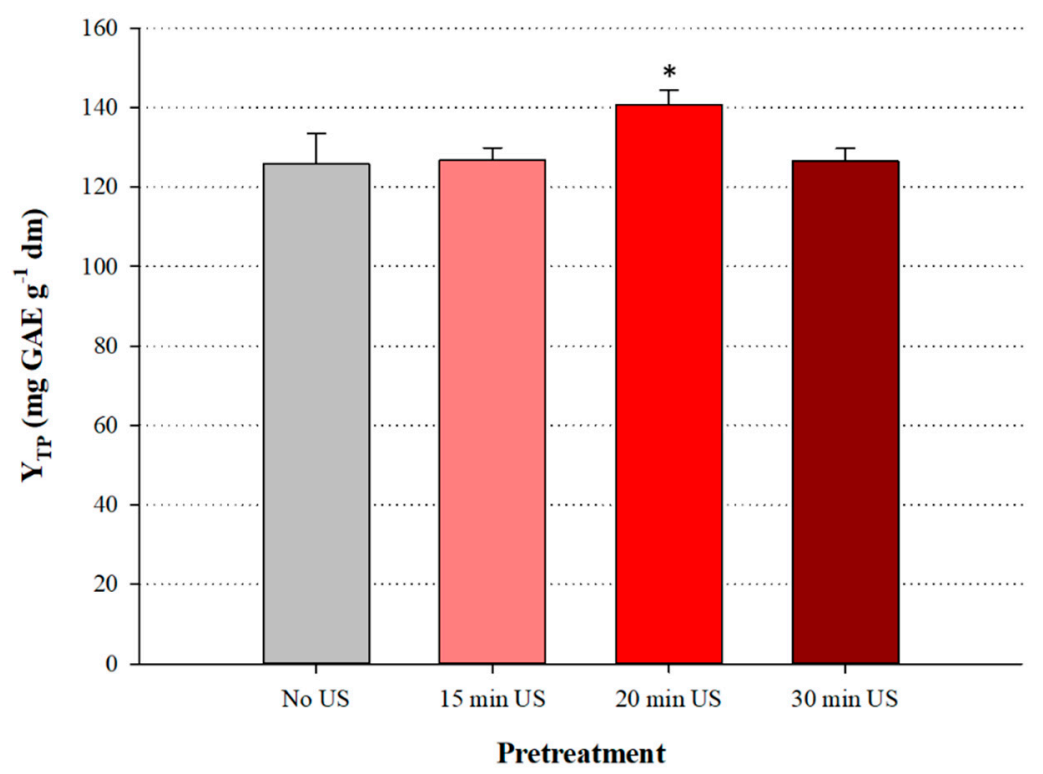

Figure 5. Effect of ultrasonication time on $\mathrm{Y}_{\mathrm{TP}}$. Ultrasonication was performed prior to batch-stirred tank extractions.

A further prolongation up to $30 \mathrm{~min}$ caused a decrease in $\mathrm{Y}_{\mathrm{TP}}$ to levels similar to control. Therefore, 20 min was chosen as the most efficacious ultrasonication time. Following this, a kinetic study was undertaken to examine the effect of ultrasonication on polyphenol extraction. Irrespective of the pretreatment, the model best fitted to the experimental data was a modified double reciprocal model, as described previously [39]:

$$
\mathrm{Y}_{\mathrm{TP}(t)}=\mathrm{Y}_{\mathrm{TP}(0)}+\frac{\mathrm{Y}_{\mathrm{TP}(\mathrm{s})} t}{t_{0.5}+t}
$$

where $Y_{T P(0)}$ is a fitting parameter, and $Y_{T P(s)}$ and $Y_{T P(t)}$ are the $Y_{T P}$ at saturation (equilibrium) and at any time, $t$, respectively. Since $t_{0.5}$ corresponds to the time where $50 \%$ of the $\mathrm{Y}_{\mathrm{TP}(\mathrm{s})}$ has been attained, then $2 t_{0.5}$ can be considered as the time required for the extraction to enter the regular regime $\left(t_{\mathrm{R}}\right)$, which may be regarded as the second, slow phase of the extraction. During this regime, small increases in the extraction rate are recorded within a large period [40]. $\mathrm{Y}_{\mathrm{TP}(\mathrm{s})}$ and $t_{0.5}$ were given by SigmaPlot $^{\mathrm{TM}}$ 12.5 software. Then, the initial rate of the extraction, $h$, and the second-order extraction rate, $k$, were determined as follows:

$$
\begin{gathered}
h=\frac{\mathrm{Y}_{\mathrm{TP}(\mathrm{s})}}{t_{0.5}} \\
k=\frac{1}{\mathrm{Y}_{\mathrm{TP}(\mathrm{s})} t_{0.5}}
\end{gathered}
$$

Kinetics was determined within a temperature range of 40 to $80{ }^{\circ} \mathrm{C}$ (Figure 6) in order to investigate the effect of temperature, and the data obtained are analytically presented in Table 3. Surprisingly, extraction rate constants for ultrasound-pretreated and non-pretreated extractions displayed a progressive decrease as a response to increases in temperature (Figure 7), which could be effectively described by an exponential model [41]:

$$
k=k_{0}+\mathrm{a} e^{-\mathrm{b} T}
$$

where $k$ and $k_{0}$ correspond to the second-order extraction rate and temperature-independent factor, respectively. For the non-pretreated extractions, parameters $a$ and $b$ were 0.0124 and 0.0475 , and the corresponding values for the ultrasound-pretreated extractions were 5.768 and 0.155 . This finding suggested the ultrasound-pretreated extraction to be more sensitive to temperature changes. 
Table 3. Parameters estimated using extraction kinetics to assess the effect of temperature on hop polyphenol extraction.

\begin{tabular}{|c|c|c|c|c|}
\hline \multirow[t]{2}{*}{ Temperature, $T\left({ }^{\circ} \mathrm{C}\right)$} & \multicolumn{4}{|c|}{ Kinetic Parameters } \\
\hline & $\begin{array}{c}\text { Second-Order } \\
\text { Extraction Rate, } k \\
\left(\times 10^{-3}\right)\left(\mathrm{g} \mathrm{mg}^{-1} \mathrm{~min}^{-1}\right)\end{array}$ & $\begin{array}{l}\text { Initial Extraction Rate, } \\
\quad h\left(\mathrm{mg} \mathrm{g}^{-1} \mathrm{~min}^{-1}\right)\end{array}$ & $\begin{array}{c}\mathrm{Y}_{\mathrm{TP}(\mathrm{s})} \\
\left(\mathrm{mg} \mathrm{GAE} \mathrm{g}^{-1}\right)\end{array}$ & $\begin{array}{l}\text { Half Time, } t_{0.5} \\
\text { (min) }\end{array}$ \\
\hline \multicolumn{5}{|l|}{ No pretreatment } \\
\hline 40 & 2.40 & 30.80 & 112.41 & 3.65 \\
\hline 50 & 1.88 & 26.38 & 118.44 & 4.49 \\
\hline 60 & 1.17 & 17.77 & 123.13 & 6.93 \\
\hline 70 & 1.00 & 15.27 & 128.91 & 8.44 \\
\hline 80 & 0.92 & 16.19 & 131.17 & 8.10 \\
\hline \multicolumn{5}{|l|}{$\begin{array}{l}\text { Ultrasound-assisted } \\
\text { pretreatment }\end{array}$} \\
\hline 40 & 13.19 & 79.25 & 96.78 & 0.98 \\
\hline 50 & 4.10 & 32.51 & 108.37 & 2.74 \\
\hline 60 & 1.78 & 16.55 & 115.86 & 5.83 \\
\hline 70 & 1.69 & 20.11 & 128.49 & 5.43 \\
\hline 80 & 1.66 & 29.96 & 153.51 & 4.48 \\
\hline
\end{tabular}

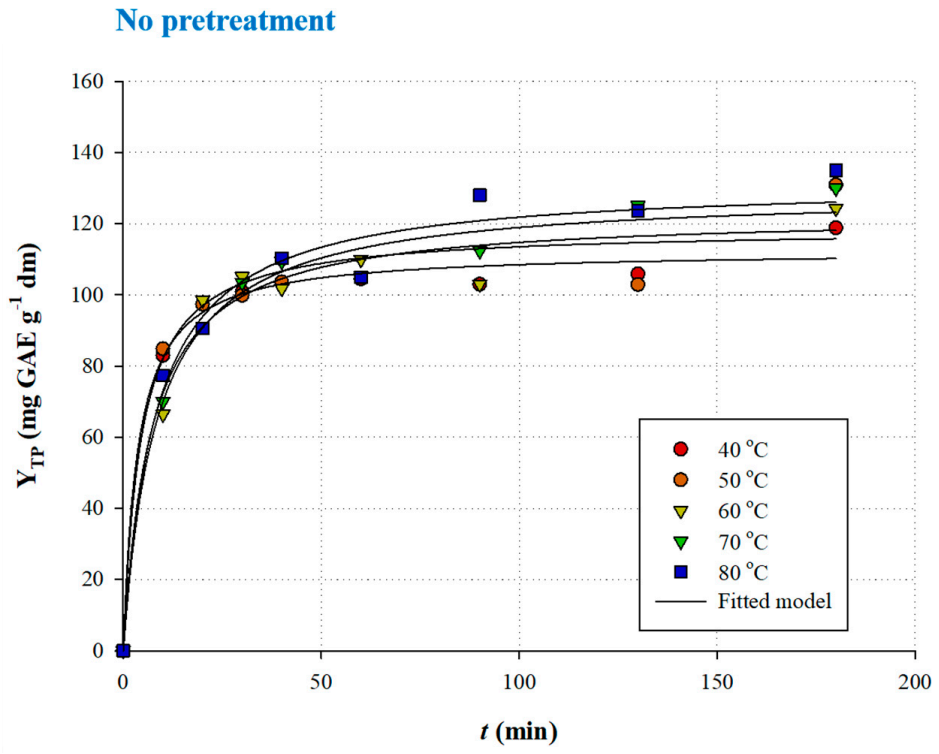

Ultrasound-assisted pretreatment

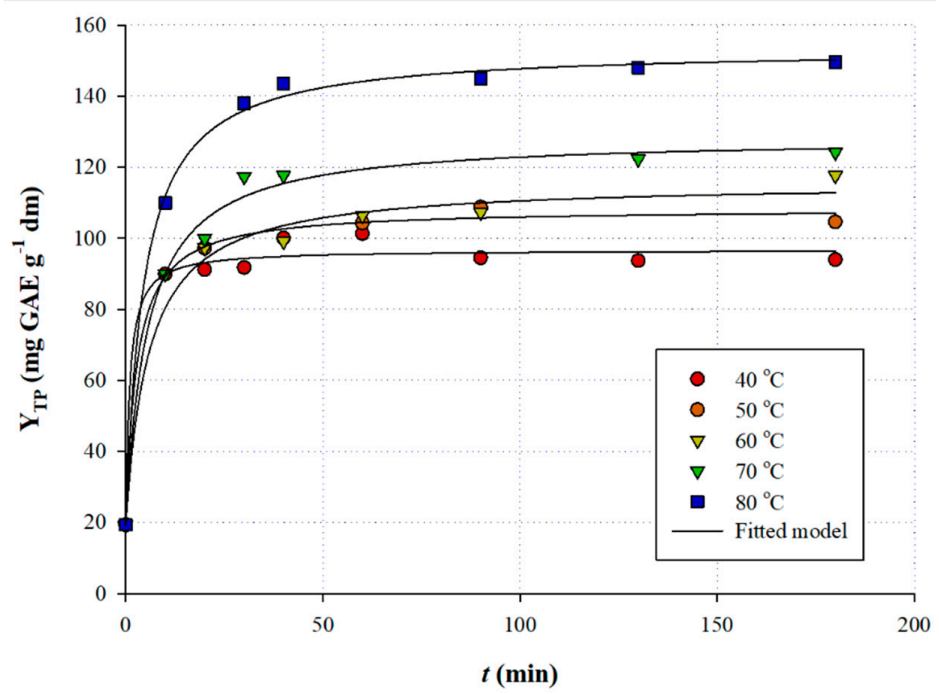

Figure 6. Kinetics of polyphenol extraction from hop, using optimised conditions $\left(C_{\mathrm{DES}}=85 \%\right.$ $(w / w), \mathrm{R}_{\mathrm{L} / \mathrm{S}}=59 \mathrm{~mL} \mathrm{~g}^{-1}$ and $\mathrm{S}_{\mathrm{S}}=688 \mathrm{rpm}$ ), with (lower plot) and without (upper plot) prior ultrasonication pretreatment. 


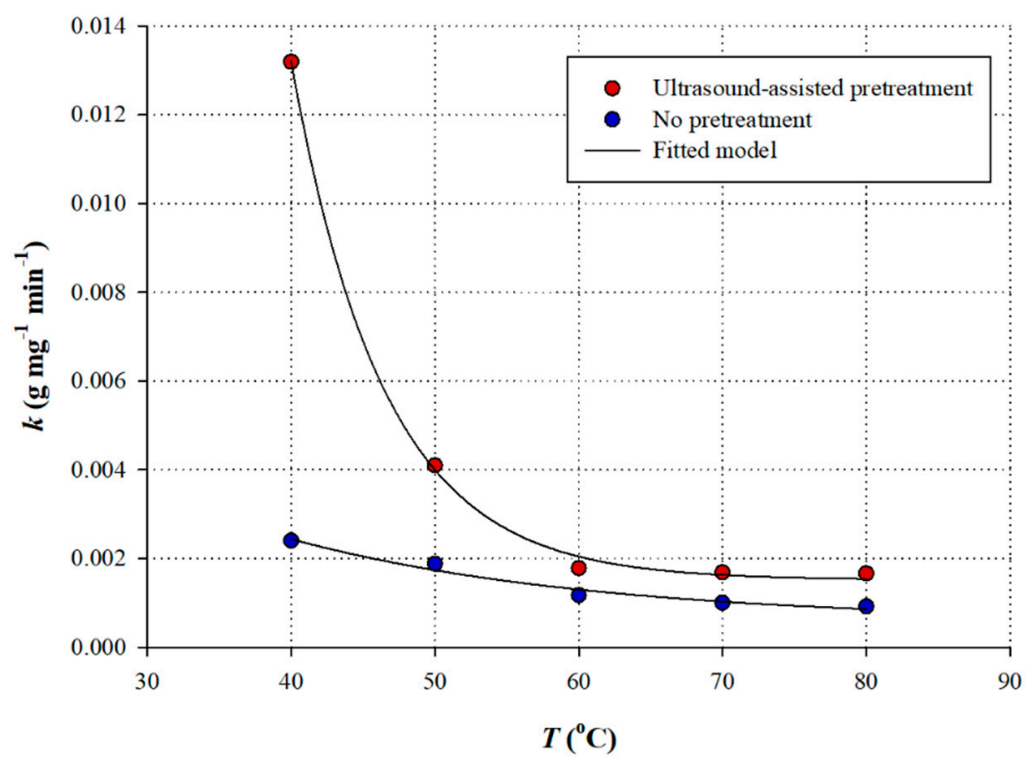

Figure 7. Plot showing the effect of temperature, $T$, on the second-order extraction rate, $k$. Extractions were carried out under optimised conditions $\left(C_{\mathrm{DES}}=85 \%(w / w), \mathrm{R}_{\mathrm{L} / \mathrm{S}}=59 \mathrm{~mL} \mathrm{~g}^{-1}\right.$ and $\left.\mathrm{S}_{\mathrm{S}}=688 \mathrm{rpm}\right)$, with and without 20 -min ultrasonication pretreatment.

The decline in the extraction rate, $k$, as temperature increased was a rather paradox phenomenon, since a number of earlier studies demonstrated that polyphenol extraction obeyed the Arrhenius model $[35,42,43]$. However, a recent examination showed that polyphenol extraction with certain glycerol-based DES may display anti-Arrhenius behaviour [33]. The authors attributed this effect to a partial disintegration of DES through hydrogen bond rupture between HBD and HBA, because of the increasing temperature. This would lead to the abolishment of the DES properties, leading to a lower solubilisation capacity of the solute (polyphenols), hence the decreased extraction rate.

It is to be noted that for any temperature tested, ultrasound-pretreated samples exhibited higher $k$, evidence that ultrasonication pretreatment may favour higher extraction rates. This argument was further corroborated by the values of the initial extraction rate, $h$, which showed a similar pattern, up to $70^{\circ} \mathrm{C}$. This would eventually lead to faster extraction, as indicated by the $t_{0.5}$ values determined (Table 3 ). For temperatures up to $70^{\circ} \mathrm{C}$, the non-pretreated extractions afforded higher $\mathrm{Y}_{\mathrm{TP}(\mathrm{s})}$, which indicated that ultrasonication pretreatment did not contribute to increasing the extraction yield, but rather suppressed polyphenol extraction. By contrast, $\mathrm{Y}_{\mathrm{TP}(\mathrm{s})}$ for the ultrasound-pretreated sample at $80^{\circ} \mathrm{C}$ was $17 \%$ higher than that of the non-pretreated one. Such a finding pointed to a temperature-dependent efficiency of the ultrasound-assisted pretreatment. This outcome contrasted previous results, which showed that ultrasound-pretreated grape pomace extraction with aqueous ethanol was more efficient than the non-pretreated one, irrespective of the temperature [38]. Presumably, differentiations in the extraction pattern may be ascribed to the nature of the solute (polyphenol structures and composition), as well as to the nature of the solvents used.

To explain such an effect, the impact of ultrasonication should be considered. Ultrasonic power provokes voids in a liquid, known as cavitation bubbles, which are responsive to the ultrasonic effect. During ultrasonication, cavitation bubbles grow up to a critical point and then collapse, releasing large amounts of energy. The combination of high temperature and high pressure might cause significant disruption to the solid particle integrity, and thus solute may be released in the liquid phase [44]. As evidence for the peculiar extraction properties of DES accumulates, a deeper insight is imminent to clarify DES behaviour in similar processes. 


\section{Conclusions}

A green extraction process was developed, using a newly designed deep eutectic solvent, to obtain hop extracts enriched in polyphenolic compounds. The process was optimised by implementing a Box-Behnken experimental design, and the effect of ultrasonication as a pretreatment step was further assessed by a kinetic study. The results obtained showed that the solvent used was an efficient extraction medium and the optimisation of the process contributed significantly to achieving high polyphenol extraction yields. All experimental variables considered, that is, the DES/water proportion, the liquid-to-solid ratio and the stirring speed, were demonstrated to be statistically significant. Ultrasonication pretreatment was shown to supress polyphenol extraction yield up to $70{ }^{\circ} \mathrm{C}$, but at $80^{\circ} \mathrm{C}$ ultrasonication boosted polyphenol recovery. The second-order extraction rates exhibited a declining trend in response to increasing temperature, and this is a phenomenon that merits a profounder investigation. Along with the recommendation of the novel deep eutectic solvent, the estimated optimised conditions under which it was developed and a pretreatment involving ultrasonication are recommended as a set of process variables that could enable the production of hop extracts highly enriched in polyphenolic substances.

Author Contributions: A.L., I.K., O.K., G.B., and E.B. carried out the experimentation and handled the raw data. S.L. and D.M. conceived the idea, designed the experiment, performed statistics, handled the data and wrote the paper.

Funding: This research was co-financed by the European Union and the Hellenic Ministry of Economy \& Development through the Operational Programme Competitiveness, Entrepreneurship and Innovation, under the call RESEARCH-CREATE-INNOVATE (project code: T1EDK-05677).

Conflicts of Interest: The authors declare no conflict of interest.

\section{Nomenclature}

$\begin{array}{ll}\mathrm{A}_{\mathrm{AR}} & \text { antiradical activity }\left(\mu \mathrm{mol} \mathrm{DPPH} \mathrm{g}{ }^{-1}\right) \\ \mathrm{P}_{\mathrm{R}} & \text { reducing power }\left(\mu \mathrm{mol} \mathrm{AAE} \mathrm{g}^{-1}\right) \\ \mathrm{R}_{\mathrm{L} / \mathrm{S}} & \text { liquid-to-solid ratio }\left(\mathrm{mL} \mathrm{g}^{-1}\right) \\ \mathrm{R}_{\mathrm{mol}}^{\mathrm{D} / \mathrm{A}} & \text { molar HBD:HBA ratio (dimensionless) } \\ t & \text { time (min) } \\ T & \text { temperature }\left({ }^{\circ} \mathrm{C}\right) \\ \mathrm{Y}_{\mathrm{TF}} & \text { yield in total flavanols }\left(\mathrm{mg} \mathrm{CtE} \mathrm{g}^{-1}\right) \\ \mathrm{Y}_{\mathrm{TFn}} & \text { yield in total flavonoids }\left(\mathrm{mg} \mathrm{RtE} \mathrm{g}^{-1}\right) \\ \mathrm{Y}_{\mathrm{TP}} & \text { yield in total polyphenols }\left(\mathrm{mg} \mathrm{GAE} \mathrm{g}^{-1}\right)\end{array}$

\section{Abbreviations}

$\begin{array}{ll}\text { AAE } & \text { ascorbic acid equivalents } \\ \text { DES } & \text { deep eutectic solvents } \\ \text { DPPH } & \text { 2,2-diphenyl-1-picrylhydrazyl radical } \\ \text { GAE } & \text { gallic acid equivalents } \\ \text { HBA } & \text { hydrogen bond acceptor } \\ \text { HBD } & \text { hydrogen bond donor } \\ \text { TPTZ } & \text { 2,4,6-tripyridyl-s-triazine } \\ \text { US } & \text { ultrasonication }\end{array}$

\section{References}

1. Van Cleemput, M.; Cattoor, K.; De Bosscher, K.; Haegeman, G.; De Keukeleire, D.; Heyerick, A. Hop (Humulus lupulus)-derived bitter acids as multipotent bioactive compounds. J. Nat. Prod. 2009, 72, 1220-1230. [CrossRef] [PubMed]

2. Zanoli, P.; Zavatti, M. Pharmacognostic and pharmacological profile of Humulus lupulus L. J. Ethnopharmacol. 2008, 116, 383-396. [CrossRef] [PubMed] 
3. Bocquet, L.; Sahpaz, S.; Hilbert, J.; Rambaud, C.; Rivière, C. Humulus lupulus L., a very popular beer ingredient and medicinal plant: Overview of its phytochemistry, its bioactivity, and its biotechnology. Phytochem. Rev. 2018, 17, 1047-1090. [CrossRef]

4. Almaguer, C.; Schönberger, C.; Gastl, M.; Arendt, E.K.; Becker, T. Humulus lupulus-A story that begs to be told. A review. J. Inst. Brew. 2014, 120, 289-314. [CrossRef]

5. Karabín, M.; Hudcová, T.; Jelínek, L.; Dostálek, P. Biologically active compounds from hops and prospects for their use. Compr. Rev. Food Sci. Food Saf. 2016, 15, 542-567. [CrossRef]

6. Dostálek, P.; Karabín, M.; Jelínek, L. Hop phytochemicals and their potential role in metabolic syndrome prevention and therapy. Molecules 2017, 22, 1761. [CrossRef]

7. Luca, S.V.; Macoveia, I.; Bujora, A.; Mirona, A.; Skalicka-Wozniakb, K.; Aprotosoaiea, A.K.; Trifan, A. Bioactivity of dietary polyphenols: The role of metabolites. Crit. Rev. Food Sci. Nutr. 2019, 7, 1-34. [CrossRef]

8. Li, A.-N.; Li, S.; Zhang, Y.-J.; Xu, X.-R.; Chen, Y.-M.; Li, H.-B. Resources and biological activities of natural polyphenols. Nutrients 2014, 6, 6020-6047. [CrossRef]

9. Shahidi, F.; Yeo, J. Bioactivities of phenolics by focusing on suppression of chronic diseases: A review. Int. J. Mol. Sci. 2018, 19, 1573. [CrossRef]

10. Belwal, T.; Ezzat, S.M.; Rastrelli, L.; Bhatt, I.D.; Daglia, M.; Baldi, A.; Devkota, H.P.; Orhan, I.E.; Patra, J.K.; Das, G. A critical analysis of extraction techniques used for botanicals: Trends, priorities, industrial uses and optimization strategies. Trends Anal. Chem. 2018, 100, 82-102. [CrossRef]

11. Herrero, M.; Ibañez, E. Green extraction processes, biorefineries and sustainability: Recovery of high added-value products from natural sources. J. Supercrit. Fluids 2018, 134, 252-259. [CrossRef]

12. Clarke, C.J.; Tu, W.-C.; Levers, O.; Bröhl, A.; Hallett, J.P. Green and sustainable solvents in chemical processes. Chem. Rev. 2018, 118, 747-800. [CrossRef] [PubMed]

13. De los Ángeles Fernández, M.; Boiteux, J.; Espino, M.; Gomez, F.V.; Silva, M.F. Natural deep eutectic solvents-mediated extractions: The way forward for sustainable analytical developments. Anal. Chim. Acta 2018, 1038, 1-10. [CrossRef] [PubMed]

14. Bubalo, M.C.; Vidović, S.; Redovniković, I.R.; Jokić, S. New perspective in extraction of plant biologically active compounds by green solvents. Food Bioprod. Process. 2018, 109, 52-73. [CrossRef]

15. Kottaras, P.; Koulianos, M.; Makris, D.P. Low-Transition temperature mixtures (LTTMs) made of bioorganic molecules: Enhanced extraction of antioxidant phenolics from industrial cereal solid wastes. Recycling 2017, 2, 3. [CrossRef]

16. Bezerra, M.A.; Santelli, R.E.; Oliveira, E.P.; Villar, L.S.; Escaleira, L.A. Response surface methodology (RSM) as a tool for optimization in analytical chemistry. Talanta 2008, 76, 965-977. [CrossRef] [PubMed]

17. Cicco, N.; Lanorte, M.T.; Paraggio, M.; Viggiano, M.; Lattanzio, V. A reproducible, rapid and inexpensive Folin-Ciocalteu micro-method in determining phenolics of plant methanol extracts. Microchem. J. 2009, 91, 107-110. [CrossRef]

18. Karakashov, B.; Grigorakis, S.; Loupassaki, S.; Mourtzinos, I.; Makris, D.P. Optimisation of organic solvent-free polyphenol extraction from Hypericum triquetrifolium Turra using Box-Behnken experimental design and kinetics. Int. J. Ind. Chem. 2015, 6, 85-92. [CrossRef]

19. Manousaki, A.; Jancheva, M.; Grigorakis, S.; Makris, D.P. Extraction of antioxidant phenolics from agri-food waste biomass using a newly designed glycerol-based natural low-transition temperature mixture: A comparison with conventional eco-friendly solvents. Recycling 2016, 1, 194-204. [CrossRef]

20. Makris, D.P.; Boskou, G.; Chiou, A.; Andrikopoulos, N.K. An investigation on factors affecting recovery of antioxidant phenolics and anthocyanins from red grape (Vitis vinifera L.) pomace employing water/ethanol-based solutions. Am. J. Food Technol. 2008, 3, 164-173. [CrossRef]

21. Shi, H.; Niki, E. Stoichiometric and kinetic studies on Ginkgo biloba extract and related antioxidants. Lipids 1998, 33, 365. [CrossRef] [PubMed]

22. Makris, D.P.; Passalidi, V.; Kallithraka, S.; Mourtzinos, I. Optimization of polyphenol extraction from red grape pomace using aqueous glycerol/tartaric acid mixtures and response surface methodology. Prep. Biochem. Biotechnol. 2016, 46, 176-182. [CrossRef] [PubMed]

23. Huang, Y.; Feng, F.; Jiang, J.; Qiao, Y.; Wu, T.; Voglmeir, J.; Chen, Z.-G. Green and efficient extraction of rutin from tartary buckwheat hull by using natural deep eutectic solvents. Food Chem. 2017, 221, 1400-1405. [CrossRef] [PubMed] 
24. Cui, Q.; Peng, X.; Yao, X.-H.; Wei, Z.-F.; Luo, M.; Wang, W.; Zhao, C.-J.; Fu, Y.-J.; Zu, Y.-G. Deep eutectic solvent-based microwave-assisted extraction of genistin, genistein and apigenin from pigeon pea roots. Sep. Purif. Technol. 2015, 150, 63-72. [CrossRef]

25. Karageorgou, I.; Grigorakis, S.; Lalas, S.; Makris, D.P. Enhanced extraction of antioxidant polyphenols from Moringa oleifera Lam. leaves using a biomolecule-based low-transition temperature mixture. Eur. Food Res. Technol. 2017, 243, 1839-1848. [CrossRef]

26. Patsea, M.; Stefou, I.; Grigorakis, S.; Makris, D.P. Screening of natural sodium acetate-based low-transition temperature mixtures (LTTMs) for enhanced extraction of antioxidants and pigments from red vinification solid wastes. Environ. Process. 2017, 4, 123-135. [CrossRef]

27. Cui, Q.; Liu, J.-Z.; Wang, L.-T.; Kang, Y.-F.; Meng, Y.; Jiao, J.; Fu, Y.-J. Sustainable deep eutectic solvents preparation and their efficiency in extraction and enrichment of main bioactive flavonoids from sea buckthorn leaves. J. Clean. Prod. 2018, 184, 826-835. [CrossRef]

28. Athanasiadis, V.; Grigorakis, S.; Lalas, S.; Makris, D.P. Highly efficient extraction of antioxidant polyphenols from Olea europaea leaves using an eco-friendly glycerol/glycine deep eutectic solvent. Waste Biomass Valor. 2018, 9, 1985-1992. [CrossRef]

29. Bi, W.; Tian, M.; Row, K.H. Evaluation of alcohol-based deep eutectic solvent in extraction and determination of flavonoids with response surface methodology optimization. J. Chromatogr. A 2013, 1285, 22-30. [CrossRef]

30. Pinelo, M.; Sineiro, J.; Núñez, M.J. Mass transfer during continuous solid-liquid extraction of antioxidants from grape byproducts. J. Food Eng. 2006, 77, 57-63. [CrossRef]

31. Rakotondramasy-Rabesiaka, L.; Havet, J.-L.; Porte, C.; Fauduet, H. Estimation of effective diffusion and transfer rate during the protopine extraction process from Fumaria officinalis L. Sep. Purif. Technol. 2010, 76, 126-131. [CrossRef]

32. Shewale, S.; Rathod, V.K. Extraction of total phenolic content from Azadirachta indica or (neem) leaves: Kinetics study. Prep. Biochem. Biotechnol. 2018, 48, 312-320. [CrossRef] [PubMed]

33. Jancheva, M.; Grigorakis, S.; Loupassaki, S.; Makris, D.P. Optimised extraction of antioxidant polyphenols from Satureja thymbra using newly designed glycerol-based natural low-transition temperature mixtures (LTTMs). J. Appl. Res. Med. Aromat. Plants 2017, 6, 31-40. [CrossRef]

34. Dedousi, M.; Mamoudaki, V.; Grigorakis, S.; Makris, D.P. Ultrasound-assisted extraction of polyphenolic antioxidants from olive (Olea europaea) leaves using a novel glycerol/sodium-potassium tartrate low-transition temperature mixture (LTTM). Environments 2017, 4, 31. [CrossRef]

35. Slim, Z.; Jancheva, M.; Grigorakis, S.; Makris, D.P. Polyphenol extraction from Origanum dictamnus using low-transition temperature mixtures composed of glycerol and organic salts: Effect of organic anion carbon chain length. Chem. Eng. Commun. 2018, 205, 1494-1506. [CrossRef]

36. Vetal, M.D.; Lade, V.G.; Rathod, V.K. Extraction of ursolic acid from Ocimum sanctum by ultrasound: Process intensification and kinetic studies. Chem. Eng. Process. 2013, 69, 24-30. [CrossRef]

37. Albuquerque, B.R.; Prieto, M.; Vazquez, J.; Barreiro, M.F.; Barros, L.; Ferreira, I.C. Recovery of bioactive compounds from Arbutus unedo L. fruits: Comparative optimization study of maceration/ microwave/ultrasound extraction techniques. Food Res. Int. 2018, 109, 455-471. [CrossRef] [PubMed]

38. Nayak, A.; Bhushan, B.; Rosales, A.; Turienzo, L.R.; Cortina, J. Valorisation potential of Cabernet grape pomace for the recovery of polyphenols: Process intensification, optimisation and study of kinetics. Food Bioprod. Process. 2018, 109, 74-85. [CrossRef]

39. Karageorgou, I.; Grigorakis, S.; Lalas, S.; Mourtzinos, I.; Makris, D.P. Incorporation of 2-hydroxypropyl $\beta$-cyclodextrin in a biomolecule-based low-transition temperature mixture (LTTM) boosts efficiency of polyphenol extraction from Moringa oleifera Lam leaves. J. Appl. Res. Med. Aromat. Plants 2018, 9, 62-69. [CrossRef]

40. Seikova, I.; Simeonov, E.; Ivanova, E. Protein leaching from tomato seed-Experimental kinetics and prediction of effective diffusivity. J. Food Eng. 2004, 61, 165-171. [CrossRef]

41. Peleg, M.; Normand, M.D.; Corradini, M.G. The Arrhenius equation revisited. Crit. Rev. Food Sci. Nutr. 2012, 52, 830-851. [CrossRef] [PubMed]

42. Shehata, E.; Grigorakis, S.; Loupassaki, S.; Makris, D.P. Extraction optimisation using water/glycerol for the efficient recovery of polyphenolic antioxidants from two Artemisia species. Sep. Purif. Technol. 2015, 149, 462-469. [CrossRef] 
43. Trasanidou, D.; Apostolakis, A.; Makris, D.P. Development of a green process for the preparation of antioxidant and pigment-enriched extracts from winery solid wastes using response surface methodology and kinetics. Chem. Eng. Commun. 2016, 203, 1317-1325. [CrossRef]

44. Chemat, F.; Khan, M.K. Applications of ultrasound in food technology: Processing, preservation and extraction. Ultrason. Sonochem. 2011, 18, 813-835. [CrossRef] [PubMed]

(C) 2019 by the authors. Licensee MDPI, Basel, Switzerland. This article is an open access article distributed under the terms and conditions of the Creative Commons Attribution

(CC BY) license (http://creativecommons.org/licenses/by/4.0/). 